
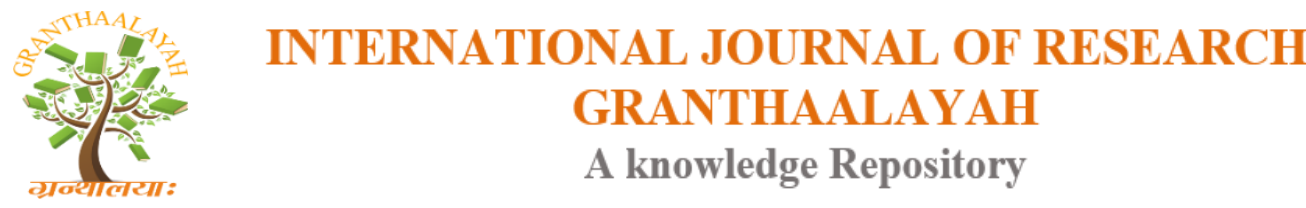

Science

\title{
STUDY OF CRANIAL ULTRASOUND FINDING IN HYPOXIC ISCHEMIC ENCEPHALOPATHY IN TERM INFANTS AND ITS CLINICAL CORELATION
}

\author{
Bijay Laxmi Malick ${ }^{1}$, Mangal Charan Murmu², Anil Kumar Mohanty ${ }^{3}$ \\ ${ }^{1}$ Assistant Professor, S C B Medical College, Cuttack, Odisha, India \\ ${ }^{2}$ Associate Professor of Pediatrics, S C B Medical College, Cuttack, Odisha, India \\ ${ }^{3}$ Professor, S C B Medical College, Cuttack, Odisha, India
}

\begin{abstract}
Introduction: Incidence of Hypoxic Ischemic Encephalopathy (HIE) is 2-4 per 1000 live birth in USA, 1.8 per 1000 live births in Sweden, 3.8 per 1000 term live births in Australia. In India the incidence of HIE is 10-15 per 1000 live birth. The survivors from severe HIE develop cerebral palsy and mental handicaps as high as $50 \%$. Concurrent use of cranial ultra sound and clinical staging systems are evolving to predict the prognosis. Objective: To study the cranial ultrasonogrphic finding in HIE Infants and its clinical correlation and prediction of outcome. Method: it is a prospective clinical study of 120 baby suffering from hypoxic ischemic encephalopathy. Result: Co-relation of initial cranial ultra sonography grading with mortality and sequel showed an increasing trend as the ultrasonography grading increases, with $51.4 \%$ mortality in grade -III, $18.5 \%$ in grade-II and $15.4 \%$ in grade -I. Seqele $48.6 \%$ was observed only in gradeIII sonographic abnormality. Conclusion: Sonographic grading is more accurate than the clinical staging in predicting recovery, mortality and sequel.
\end{abstract}

Keywords: Hypoxic Ischemic Encephalopathy; APGAR Score; Cranial Ultrasound.

Cite This Article: Bijay Laxmi Malick, Mangal Charan Murmu, and Anil Kumar Mohanty. (2018). "STUDY OF CRANIAL ULTRASOUND FINDING IN HYPOXIC ISCHEMIC ENCEPHALOPATHY IN TERM INFANTS AND ITS CLINICAL CORELATION." International Journal of Research - Granthaalayah, 6(4), 157-165. https://doi.org/10.29121/granthaalayah.v6.i4.2018.1638.

\section{Introduction}

Hypoxic ischemic encephalopathy is the term used to designate the clinical and neuropathologic finding of an encephalopathy that occurs in an infant who has experienced a significant episode of intra-partum asphyxia[1]. It is important to recognise that the child who subsequently will develop cerebral palsy secondary to intra-partum asphyxia will demonstrate unequivocal clinical signs of HIE during the neonatal period, usually during the first 2 to 7 days of life. Cerebral hypoxiaischemia (asphyxia) occurring in the fetus and newborn infant is a major cause of acute mortality 
and chronic neurological disability in survivors,[2] The incidence of perinatal asphyxia is about 1.0 to $1.5 \%$ of live births in most centres and is inversely related to gestational age and birth weight ,lowering considerably in later gestation. It occurs in 9\%of infants less than 36 weeks and in $0.5 \%$ of infants more than 36 weeks of gestation accounting for $20 \%$ of perinatal death $[3,4]$. The incidence is higher in term infants of diabetic ot toxaemic mothers, these factors correlates less well in preterm infants. The Sarnat clinical stages are commonly used to estimate the severity of asphyxia insult to infants more than 36 weeks of gestation age[5].

In recent years ultrasonographic grading and correlation with clinical staging are being increasingly practised. Concurrent use of sonographic grading with clinical staging systems are evolving to predict ultimate prognosis[6]. However certain imaging futures are independently associated with poor prognosis. Since birth asphyxia is one of the leading cause of neobatal motality in our country and as trasfontanalle ultrasonography is a non invasive relatively inexpensiveand easily repeatable bedside imaging modality, it was decided to take up the study of cranial ultrasound finding in hypoxic ischemic encephalopathy in term infants and its clinical correlations.

\section{Method}

The study was conducted at S.V.P. Post Graduate Institute of pediatrcs, S C B Medical College, Cuttack from September 2015 to August 2017. It's a prospective study. We studied 120 number of infants.

\section{Inclusion Criteria}

The inclusion criteria are

i. $\quad$ Documented APGAR score of 0-3 persisting for longer than 5 minutes.

ii. Neonatal neurological manifestations like convulsion, coma, hypotonia, lethargy.

iii. Multiple organ involvement (brain, liver, lungs, heart, kidney, intestine)

iv. History of difficult labour with poor or no cry immediately after birth.

\section{Exclusion Criteria}

i. Insult not due to hypoxic ischemia of brain such as complication of pregnancy, labour that do not support the occurrence of asphyxia.

ii. Injury to brain caused by metabolic derangement, cerebral dysgenesis, infections, prematurity.

iii. Infants left against medical advice.

iv. Infants with congenital malformations.

v. Death within half an hour of admission.

vi. In infant where at least two cranial ultrasound could not be done.

All the babies were examined on admission physically, detail history was taken in a Performa to avoid bias. Special importance was given to gestational age, nature of delivery, duration of $2^{\text {nd }}$ stage of labour and evidence of intra uterine asphyxia. All the babies were clinically graded according to severity of HIE as per Levens clinical grading and "Sarnat and Sarnat" staging. The 
baby who became very sick needing Neonatal Intensive Care were being admitted to NICU (Neonatal Intensive Care Unit). The baby who were included in study underwent relevant laboratory investigations as needed. Trans cranial ultra sonogram was done in every neonate within 24 hours, at 4 weeks and at 12 weeks to evaluate the resolution and sequele. All the investigations were done in SVP PG Institute of Pediatrics, S C B Medical College, Cuttack.

\section{Investigations}

The following investigations were done in every baby included in this study.
i. Complete blood count,
ii. Random blood sugar,
iii. Serum electrolytes,
iv. Sepsis screen,
v. Serum urea and creatinine,
vi. Cranial ultrasonography.

Other investigations were done as and when required according to the need.

\section{Cranial Ultrasound}

Using the real time $2 \mathrm{D}$ Scanner with high frequency (7.5Mhz) transducer Cranial ultrasound was done. Scans were performed through anterior fontanelle in both coronal and sagittal planes. Transducer was moved along parasagittal plane and anterior-posterior plane to acquire the image of whole hemisphere. Axial scanning was done through mastoid fontanelle for evaluation of posterior fossa and brain stem. Axial posterior fontanels scanning was done in selective cases for evaluation occipital horns for ventricular clot.

After all the investigation were done and tabulated

Table 1: Incidence of HIE cases among hospitalised children

\begin{tabular}{|l|l|l|l|l|l|l|l|l|}
\hline SI No & $\begin{array}{c}\text { Total no } \\
\text { of indoor } \\
\text { admission }\end{array}$ & $\begin{array}{c}\text { Total no. } \\
\text { of HIE } \\
\text { cases } \\
\text { admitted }\end{array}$ & $\%$ & $\begin{array}{c}\text { Total } \\
\text { number of } \\
\text { newborns } \\
\text { admitted to } \\
\text { NICU }\end{array}$ & $\begin{array}{c}\text { Total } \\
\text { number } \\
\text { of HIE } \\
\text { admitted } \\
\text { to NICU }\end{array}$ & $\%$ & $\begin{array}{c}\text { Number } \\
\text { of cases } \\
\text { excluded }\end{array}$ & $\begin{array}{c}\text { Number } \\
\text { of cases } \\
\text { included }\end{array}$ \\
\hline 1 & 15071 & 633 & 4.2 & 972 & 283 & 29 & 163 & 120 \\
\hline
\end{tabular}

The overall incidence of HIE cases among hospitalised children is $4.2 \%$ whereas ICU admissions of HIE cases constitute $44.7 \%$ of all ICU admissions. After applying exclusion criteria 120 cases included in the study.

Table 2: Clinical presentation of HIE at admission to ICU $(n=120)$

\begin{tabular}{|l|l|l|l|}
\hline Sl no & \multicolumn{1}{|c|}{ Clinical presentation } & No. of cases & Percentage \\
\hline 1 & Level of consciousness & & \\
& Hyper alert & 44 & 37 \\
& Coma & 34 & 28.57 \\
& Stuporous & 10 & 8.11 \\
\hline
\end{tabular}


[Malick et. al., Vol.6 (Iss.4): April 2018]

\begin{tabular}{|l|l|l|l|}
\hline & Lethargic & 52 & 32.8 \\
\hline 2 & seizures & 39 & 32.8 \\
\hline 3 & Muscle tone & & \\
& a. Hypotonia & 59 & 49 \\
& b. Flacid & 16 & 13.63 \\
\hline 4 & Behavioral abnormalities & & \\
& Poor feeding & 117 & 97.4 \\
& Irritability & 45 & 37.33 \\
& Excessive cry & 18 & 15.25 \\
& Sleepiness & 30 & 25.32 \\
\hline 5 & Reflexes: Neonatal & & \\
& Normal & 44 & 37 \\
& Depressed & 59 & 49.35 \\
& Absent & 20 & 16.63 \\
& Exaggerated & - & - \\
& Reflexes: Deep Tendon Reflex & & \\
& Normal & 41 & 34 \\
& Depressed & 6 & 4.87 \\
& Absent & 10 & 8.76 \\
& Exaggerated & 84 & 69.8 \\
\hline 6 & Apnea & & \\
\hline 7 & Papillary finding & 45 & 38 \\
& Mydriasis & & \\
& Miosis & 44 & 37 \\
& Mid position / Unequal & 39 & 32.8 \\
\hline 8 & Posture & 16 & 13.83 \\
\hline & Mild distal flexon & & \\
& Strong distal flexon & 72 & 59.74 \\
\hline 9 & Intermittent decebration & 39 & 32.8 \\
\hline 10 & Pranial nerves palsy & 9 & 7.46 \\
\hline 11 & Irregular respiration failure & 0 & 0 \\
\hline 12 & Respiratory distress & 3 & 2.59 \\
\hline 13 & Jaundice & 7 & 6.16 \\
\hline 14 & Abdominal distention & 3 & 2.27 \\
\hline 15 & Acute renal failure & 5 & 4.22 \\
\hline & & 9 & 1.94 \\
\hline & 2 & \\
\hline & & \\
\hline & & \\
\hline & & \\
\hline
\end{tabular}

Altered sensorium in the form of lethargy was observed in $43.5 \%$, hyper alert state in $37 \%$ and coma in $28.6 \%$ cases. Seizure occurred in $33 \%$ cases. Hypotonia were observed in $49 \%$ and complete flaccidity in $13.6 \%$ of cases. Behavioral abnormalities in the form of poor feeding was seen in 97.45 cases, irritability in $37.3 \%$ and sleepiness $25.3 \%$ of cases and excessive cry only in $15 \%$ of cases. Almost half of cases have depressed neonatal reflexes and it was absent on $16.6 \%$ of cases. Apnea was observed in 38\% of cases. $93 \%$ of cases had papillary abnormalities and $100 \%$ had posture abnormalities including $7.5 \%$ with intermittent decerebration. As to other organ involvement irregular respiration was seen in $6.2 \%$ of cases, respiratory distress in $2.3 \%$ of cases, 
circulatory failure in $2.6 \%$ of cases, jaundice in $4.2 \%$ cases, ARF in $2 \%$ and abdominal distention in $8.1 \%$ of cases.

Table 3: Transcranial ultra sonogram findings in HIE babies $(n=120)$

\begin{tabular}{|l|l|l|l|l|}
\hline Sl no & \multicolumn{1}{|c|}{ USG finding } & \multicolumn{1}{|c|}{ Pre-term $(\mathbf{n}=15)$} & \multicolumn{1}{|c|}{ Term $(\mathbf{n}=\mathbf{1 0 5})$} & \multicolumn{1}{|c|}{ Total } \\
\hline 1 & Normal study & $9(60 \%)$ & $7(6.7 \%)$ & $16(13.3 \%)$ \\
\hline 2 & Cerebral edema & & $86(81.9 \%)$ & $86(71.6 \%)$ \\
\hline 3 & $\begin{array}{l}\text { Intra Parenchymal } \\
\text { hemorrhage }\end{array}$ & $3(20 \%)$ & $9(8.6 \%)$ & $12(10 \%)$ \\
\hline 4 & $\begin{array}{l}\text { Sub Ependymal } \\
\text { hemorrhage }\end{array}$ & $1(6.66 \%)$ & $3(2.8 \%)$ & $4(3.4 \%)$ \\
\hline 5 & $\begin{array}{l}\text { Periventricular } \\
\text { hyperechogenecity }\end{array}$ & $2(13.3 \%)$ & - & $2(1.7 \%)$ \\
\hline
\end{tabular}

Gross USG findings in HIE cases showed normal study in $13.3 \%$, cerebral edema in $71.6 \%$ and periventricular hyperechogenicity in $1.7 \%$.

Table 4: USG grading in HIE CASES

\begin{tabular}{|c|c|c|c|c|c|c|}
\hline \multirow[t]{2}{*}{ SI No } & \multirow{2}{*}{$\begin{array}{c}\text { Gestatinal } \\
\text { Age }\end{array}$} & \multirow{2}{*}{$\begin{array}{c}\text { No. of } \\
\text { cases }\end{array}$} & \multicolumn{4}{|c|}{ USG GRADING } \\
\hline & & & Normal & Grade -I & Grade -II & Grade -III \\
\hline 1 & Preterm & 15 & 4 & $4(3.33 \%)$ & $3(2.5 \%)$ & $4(3.33 \%)$ \\
\hline 2 & Term & 102 & 12 & $9(7.5 \%)$ & $51(42.5 \%)$ & $30(25 \%)$ \\
\hline 3 & Post term & 3 & 0 & 0 & 0 & $3(2.5 \%)$ \\
\hline 4 & Total $n=120$ & 120 & $16(13.3 \%)$ & $13(10.8 \%)$ & $54(45 \%)$ & $37(30.8 \%)$ \\
\hline
\end{tabular}

By cranial USG $1.8 \%$ were in grade -I. $30.8 \%$ were in grade -III and majority were in grade $\mathrm{II}(45 \%)$. Among preterm infants babies majority were in Grade-I and Grade -III each in $3.3 \%$ in term babies majority were in Grade-II $42.5 \%$ followed by $25 \%$ in Grade-III and all post term infants were in Grade-III.

Table 5: Outcome according to initial USG Grading

\begin{tabular}{|l|l|l|l|l|l|l|l|l|}
\hline \multirow{2}{*}{ Sl. No } & \multirow{2}{*}{$\begin{array}{l}\text { USG } \\
\text { Grading }\end{array}$} & \multirow{2}{*}{ No. of cases } & \multicolumn{2}{|c|}{ Death } & \multicolumn{2}{c|}{ Sequele } & \multicolumn{2}{c|}{ Recovered } \\
\cline { 3 - 9 } & & No of cases & \% & No of cases & \% & No of cases & \% \\
\hline 1 & I & 13 & 2 & 15.4 & - & - & 11 & 84.4 \\
\hline 2 & II & 54 & 10 & 18.5 & - & - & 44 & 81.5 \\
\hline 3 & III & 37 & 19 & 51.4 & 18 & 48.6 & - & - \\
\hline 4 & Total & 104 & 31 & 29.8 & 18 & 17.3 & 55 & 52.9 \\
\hline
\end{tabular}

Ultimate outcome of 104 neonates with initial USG abnormality showed recovery in $53 \%$ of cases mortality of cases and sequel in $17 \%$ of cases. New born infants with grade -I USG abnormality had mortality in $15.4 \%$ and the remaining $84.6 \%$ had completely recovery. Neonates $(n=54)$ with grade-II USG abnormality showed $81.5 \%$ recovery mortality in $18.5 \%$ and no sequel. Among 37 neonates with grade-III USG abnormality none recovered, $51.4 \%$ died and $48.6 \%$ had sequele. 
Table 6: Follow up USG in HIE cases at 4 weeks \& 12 weeks

\begin{tabular}{|c|c|c|c|c|c|c|c|c|}
\hline \multirow{3}{*}{$\begin{array}{l}\text { Sl } \\
\text { No }\end{array}$} & \multirow{3}{*}{$\begin{array}{l}\text { USG } \\
\text { Grade }\end{array}$} & \multirow{3}{*}{$\begin{array}{c}\text { No of } \\
\text { Survivor }\end{array}$} & \multicolumn{3}{|c|}{ USG at 4 weeks } & \multicolumn{3}{|c|}{ USG at 12 weeks } \\
\hline & & & \multicolumn{2}{|c|}{$\begin{array}{l}\text { Parenchymal } \\
\text { echogenicity }\end{array}$} & \multirow[t]{2}{*}{ Atropy } & \multicolumn{2}{|c|}{$\begin{array}{l}\text { Parenchymal } \\
\text { echogenicity }\end{array}$} & \multirow[t]{2}{*}{ Atropy } \\
\hline & & & $\begin{array}{c}\text { No } \\
\text { resolution }\end{array}$ & Resolution & & $\begin{array}{c}\text { No } \\
\text { resolution }\end{array}$ & Resolution & \\
\hline 1 & I & 11 & $4 \bullet(36.4 \%)$ & $7(63.6 \%)$ & - & - & $4(100 \%)$ & - \\
\hline 2 & II & 44 & $24(54.5 \%)$ & $20(45.5 \%)$ & - & - & $24(54.5 \%)$ & - \\
\hline 3 & III & 18 & 18 (100\%) & - & - & $14(77.8 \%)$ & - & 4 \\
\hline 4 & Total & 73 & $46(63 \%)$ & $27(37 \%)$ & - & $14(30.4 \%)$ & $28(60.9 \%)$ & 4 \\
\hline
\end{tabular}

$\checkmark 2$ cases had died earlier, 10 cases had died earlier, 19 cases had died earlier

Follow up USG at 4 weeks and 12 weeks were done for survivors of HIE cases. Of 11 neonates grade -I USG abnormality (15\%),63.6\% had complete resolution and $36.4 \%$ had no resolution by 4 weeks, by 12 weeks these infants showed complete resolution and recovered fully. Of 44 neonates with grade-II USG abnormality (18.5\%), 45.5\% showed complete resolution and 54.5\% had no resolution by 4 weeks. Repeat USG at 12 weeks showed complete resolution of all the cases $(54.5 \%)$. In grade grade-III $(n=18) 100 \%$ had no resolution by 4 weeks, at 12 weeks $77.8 \%$ persisted with parenchymal hyperechogenecity and $22.2 \%$ showed cerebral atropy.

\section{Discussion}

The incidence of HIE cases from total hospital admissions is 4.2\%. But HIE cases constitute 29\% of all new born admitted to ICU. it is reported in the national neonatal database that the incidence of birth asphyxia is around 5\%. Prakas $\mathrm{J}$ et al [7]reported incidence of birth asphyxia to be $18.85 \%$ among hospitalized neonates in National Institute of Child Health, Karachi. Vasudevan A et al[8] in a retrospective study in a PICU in Northern India observed birth asphyxia in $11.2 \%$ of all ICU admissions. The total newborn admission to ICU during the study period was 972, of which HIE formed 29\% which is much higher than the reported of above authors. Raghvendra Narayan[9] found 25\% of admitted case of NICU were HIE. About 18.42\% of HIE cases were being reported of all admission of NICU by Preeti R et al, 2018[10].

Snyder ey et al [11]1991 observed poor feeding in 64\% abnormal muscle tone in 70\%, seizure in $30 \%$, Apnea in $18 \%$ of cases and loss of neonatal reflexes in $64 \%$ of cases. Pandey VP [12]reported apneic attacks in 66\% of affected infants whereas Bergman et al[13] observed apneic spell in $22 \%$ of term infants with asphyxia. Brown observed seizures in 50\% of asphyxiated cases; Mulligan et al [14]observed seizure in 52\% of cases but Leblanc and O Gorman[15] reported 30\% with seizures.

The observations of the above authors shows conflicting data on different clinical features due to asphyxia. difference with our figures and the difference between the authors is probably due to different sample size, different levels of obstetric care and differing maternal conditions in the study quoted. Martin ancil et al [16]reported single organ involved in $25 \%$, two organ involved in $34 \%$ and 3 organ involved in 9\%. Kidney involvement was observed in 50\%, CNS in 28\%, CVS in $25 \%$ and pulmonary system in $23 \%$. Although various organ involvements in our series were not similar to the finding of above authors, $25 \%$ of our case had various combinations of 
multiple organ involvements. Our under reporting of multiple organ involvement could be due to lack of sophisticated investigations to early organ dysfunctions.

Cranial USG of brain in HIE shows normal study in $13.3 \%$, cerebral edema in $71.6 \%$, intraparenchymal haemorrhage in $10 \%$, sub ependymal haemorrhage in $3.4 \%$ and periventricular hyperechogenicity in $1.7 \%$ of cases. Cally J. Tann et al [17] found no abnormality in $45.1 \%$ (83/184) of cases. Zhu L et al [18] from china reported intracranial hemorrage $18.5 \%$ and $10.4 \%$ in which cerebral edema. Our combined figure of hemorrage $13.4 \%$ is lower than observed. Anand $\mathrm{N}$ K et al [19]in a study in Safdarjung hospital New delhi observed cerebral edema in $86 \%$ and normal study in $14 \%$ which is similar to our study. However, the periventrcular echogenicity of $6.6 \%$ is much higher than our figure $1.7 \%$. Prithviraj, et al [20] found $46 \%$ of cases to be normal neuroscan, $38 \%$ to be cerebral edema.

The ultrasonographic grading of HIE found in our study were $10.8 \%$ in grade I, $30.8 \%$ in grade III, \& 45\% were in grade-II. There was no USG abnormality in $13.3 \%$ cases. Among preterm infants majority were in grade-I and grade-III each in 3.3\%. in term babies majorities were in grade -III $(42.5 \%)$ followed by $25 \%$ in grade - III and all post term infants were in grade-III. Indira Raghupathy[21] in a study of HIE cases in child trust hospital from may 1986 to august 1990 observed grade-I ultrasound abnormality in $46.5 \%$ cases, $34.8 \%$ in grade-II, $18.6 \%$ in grade -III HIE cases which is much different from the present study. This difference is probably due to more severe asphyxiated infants in the present series than those of the author for which grade-II and grade -III numbers were much higher $(75.8 \%)$ as against $53.4 \%$ in the same grades of the author. Clinical stage-II disease had positive co-relation of $58.7 \%$ in grade-II Sonographic abnormality. $10 \%$ had grade -III sonographic abnormality which shows under diagnosis of clinical staging of these cases. No definite sonographic abnormality was seen in $17.4 \%$ cases of clinical stage-II disease showing clinical over diagnosis in these cases. Stage -III clinical disease co-relates well with sonographic grade-III abnormality in $100 \%$ cases.

At 4 weeks 2 infaints had already died, in grade -I, 4 had no resolution of parenchymal hyperechogenecity, 7 had complete resolution. At 12 weeks there was no USG abnormality in the survivors indicating full recovery. In grade-II, 10 cases had died and by 4 weeks $45.5 \%$ had total resolution and $54.5 \%$ had no resolution. From these non-resolving cases, all cases had complete resolution of USG abnormality by 12 weeks. In grade-III ,19 infants had died and 100\% showed no resolution at 4 weeks. At 12 WEEKS $77.8 \%$ of these persisted with no resolution and $22.2 \%$ developed cerebral atrophy. Overall out come of 73 survivors $37 \%$ had resolution and $63 \%$ no resolution at 4 weeks and of these non-resolving cases $30.4 \%$ persisted as such, $60.9 \%$ showed complete resolution and $8.7 \%$ developed cerebral atrophy at 12 weeks.

Anand N K et al [19], 1994 reported cerebral atrophy in 21\% and persistent sonographic abnormality in 7\% and no abnormality in 51\% cases. Mejaski et al [22],2006 reported in a follow up of 10 infants with grade-III HIE that $100 \%$ developed severe cerebral atrophy on follow up of by ultrasound. Our figure of $22 \%$ of cerebral atrophy is similar with the study of Anand NK et al [19]. There is no other comparable literature for comparison of our finding. 


\section{Summary}

The Incidence of HIE is $4.2 \%$ and constitute $29 \%$ of all Neonatal admissions to NICU. Term babies constitute $85 \%$ of all HIE cases. Lethargy (43.5\%), seizures (33\%), hypotonia (49\%), poor feeding (97\%), depressed neonatal reflex (49.3\%), apnea (38\%) papillary abnormality (70\%) were the major clinical presentation. Clinical stage-II was $79 \%$ in term babies and $73 \%$ in preterm. Cerebral edema was the major sonographic finding inn $72 \%$ of cases and $13 \%$ had normal sonographic findings. Sonographic grading of HIE cases reveals grade-II finding in the majority (45\%) followed by grade-III in $31 \%$. Complete recovery was observed in $59 \%$, death in $26 \%$ and sequel in $15 \%$. Mortality was highest in stage -III in $68 \%$ and sequel in $32 \%$ without recovery in a single case. In stage-II $13 \%$ died there was no sequel, rest $77 \%$ recovered.

Correlation of initial USG grading with mortality and sequel showed an increasing trend as the USG grading increases, with $51.4 \%$ mortality in grade - III, $18.5 \%$ in grade-II and $15.4 \%$ in gradeI. Sequele $48.6 \%$ was observed only in grade -III sonographic abnormality. In sonographic positive cases from grade-I, 36.4\% showed no resolution at 4 weeks but completely resolved by 12 weeks. In grade-II positive cases $54.5 \%$ showed no resolution at 4 weeks which completely resolved by 12 weeks. However, in grade-III abnormality $100 \%$ showed no resolution at 4 weeks and by 12 weeks $78 \%$ had no resolution and $22 \%$ showed features of cerebral atrophy. Overall sonographic resolution in $75.3 \%$ and persistence of abnormality remained in $24.7 \%$

\section{Conclusion}

Out of all HIE admission $45 \%$ required NICU care, mostly in first 3 days of life. Male, low birth weight babies are at high risk of HIE. $75 \%$ of HIE cases were from institutional deliveries, indicating poor delivery management and inadequate neonatal resuscitation. Cerebral edema and stage-II HIE are the major presentation. Sonograpgic grading is more accurate than the clinical staging in predicting recovery, mortality and sequel.

\section{References}

[1] Alfred W.BrannJr. Hypoxic Ischemic Encephalopathy (Asphyxia) Pediatric Clinics of North America Volume 33, Issue 3, June 1986, Pages 451-464

[2] Robert C. Vannucci Hypoxic-ischemic encephalopathy Amer J Perinatol 2000; Volume 17(Number 03): 113-120

[3] Jennifer J.Kurinczuk, MelanieWhite-Koning, Nadia Badawi Epidemiology of neonatal encephalopathy and hypoxic-ischaemic encephalopathy, Early Human Development, Volume 86, Issue 6, June 2010, Pages 329-338

[4] Julie Smith, Louise Well, Keith Dodd, The continuing fall in incidence of hypoxic-ischaemic encephalopathy in term infants; Br J Obstet Gynaecol 107,461-466

[5] Sarnat HB, Sarnat MS: Neonatal encephalopathy following fetal distress: A clinical and electroencephalographic study. Arch Neurol 1976; 33: 695-706.

[6] Margaretha J. Brouwer, Britt J. M. van Kooij, Ingrid C. van Haastert, Corine Koopman-Esseboom, 1Floris Groenendaal, Linda S. de Vries, and Manon J. N. L. Benders Sequential Cranial Ultrasound and Cerebellar Diffusion Weighted Imaging Contribute to the Early Prognosis of Neurodevelopmental Outcome in Preterm Infants PLoS One. 2014; 9(10): e109556.

[7] Prakash J,Das N Pattern of admission to neonatal unit.J Coll Physicians surg Pak 2005;15(6);3414. 
[8] Vasudevan A, Malhotra A, Lodha R, Kabra SK. Profile of neonates admitted in pediatric ICU and validation of Score for Neonatal Acute Physiology (SNAP). Indian Pediatr. 2006 Apr;43(4):3448

[9] Raghvendra Narayan A study of the pattern of admissions and outcome in a neonatal intensive care unit at high altitude. Sri Lanka Journal of Child Health, 2012: 41(2): 79-81

[10] Preeti Raikwar, Dhiraj Parihar, Manoj Rawal, epat. Arvinder Pal Singh Batra, Jeewandeep Kaur, Palkin Juneja, Ishita Kak A STUDY OF NEONATAL ADMISSION PATTERN AND OUTCOMEFROM RURAL HARYANA GJRA IF: 5.156 | IC Value: 85.78 VOLUME-7, ISSUE2, FEBRUARY-2018 • ISSN No 2277

[11] Snyder Ey1991 Cloheerty J P: Perinatal asphyxia in Clohery J.P., Stark AR (eds) Manual of Neonatal care, 3rd end. London: Little Brown and company 1991.pp393-411

[12] Pandey VP: Myocardial function and its effect over outcome in birth asphyxia M D Thesis university of Gorabhapur,1994

[13] Bergman Ira et al. Pediatrics; 75:488-496,1995

[14] Mulligan C J, Painter M J et al J-Pediatr;96 903-907, 1980

[15] O'Gorman et al jornal Pediatrics 1985

[16] Martin Ancel, A et al multiple organ involvement in perinatal asphyxia; J.Pediatr 1995;127:786.

[17] Cally J. Tann, Margaret Nakakeeto, Cornelia Hagmann, Emily L. Webb, Natasha Nyombi, Flaviah Namiiro, Kelly Harvey-Jones,1 Anita Muhumuza,6Kathy Burgoine, Alison M. Elliott, Jennifer J. Kurinczuk, Nicola J. Robertson, and Frances M. Cowan Early cranial ultrasound findings among infants with neonatal encephalopathy in Uganda: an observational study; Pediatr Res. 2016 Aug; 80(2): 190-196.

[18] Zhu L, Zhou C, Liu Y Effect of obstetric factors on neonatal hypoxic-ischemic brain injuries. Zhonghua Fu Chan Ke Za Zhi. 1995 Aug;30(8):463-6.

[19] Anand NK, Gupta AK, Lamba IM. Neurosonographic abnormalities in neonates with hypoxic ischemic encephalopathy. Indian Pediatr. 1994 Jul;31(7):767-74.

[20] Prithviraj D, Reddy B, Reddy R, Shruthi B. Neurosonogram in Critically Ill Neonates in Neonatal Intensive Care Unit. Int J Sci Stud 2016;4(1):124-128.

[21] Indira Raghupathy et al 1990 Aug cranial ultrasonogram in birth asphyxia Child Trust Hospital, Madras

[22] Mejaski-Bosnjak V, Besenski N, Lujić L, Polak J, Buljan-Flander G, Marusić-Della Marina B, Vukadin MS. Hypoxic-ischemic brain damage in term neonates--the relation of neurodevelopmental handicap to cranial ultrasound findings. Neurol Croat. 1992; 41(3):117-29

*Corresponding author.

E-mail address: mangal74murmu@ yahoo.co.in 